\title{
MONSTRUOSIDADE E CONTROLE EM SANGUE DE PANTERA (1942), DE JACQUES TOURNEUR
}

\section{MONSTROSITY AND CONTROL IN JACQUES TOURNEUR'S CAT PEOPLE (1942)}

\author{
Marina Pereira Penteado ${ }^{1}$, Tatiana Brandão de Araújo ${ }^{2}$
}

\begin{abstract}
RESUMO: Este artigo propõe uma análise do filme Sangue de Pantera (Cat People, 1942), de Jacques Tourneur, no que concerne às questões de controle intrínsecas à construção do conceito de monstruosidade, principalmente de uma monstruosidade feminina. O filme em debate foi abordado a partir de uma discussão sobre o contexto histórico e cultural estadunidense durante a Segunda Guerra Mundial, situando-o em meio às produções fílmicas do período e anteriores a ele. A influência de uma estética gótica, evidenciada pelas imagens fílmicas de um universo sombrio e pela discussão de angústias do período, também serão analisadas como forma de complementar a discussão proposta neste trabalho.
\end{abstract}

PALAVRAS-CHAVE: monstruosidade feminina; gótico; cinema

ABSTRACT: This article aims to analyze the movie Cat People (1942), directed by Jacques Tourneur, and its relation to control, something that is usually intertwined with the construction of monstrosity in art, especially when related to the feminine monster. Tourneur's movie was approached in relation to the cultural and historical context of the United States during the World War II, and by situating it among other movies from the period and before. The influence of a Gothic aesthetic, highlighted by the dark universe created in the film and by the discussion of the anxieties of the period, are also going to be analyze as a way to complement the discussion proposed in this article.

KEYWORDS: monstrous-feminine; gothic; cinema

No cinema, não temos um gênero estabelecido e reconhecido como "gótico", no entanto, temos imagens, enredos, personagens e estilos góticos em filmes. Isso se dá, como observa Masha Kavka, devido ao fato de que filmes "como uma mídia que nasceu no século $\mathrm{XX}$, chega depois [da literatura] e é um plagiador ávido e desavergonhado de formas literárias góticas anteriores"3 (KAVKA, 2002, p. 210 - Trad. Livre). Contudo, dizer que esse cinema apenas segue as convenções e características que se encontram explícitas em romances

\footnotetext{
${ }^{1}$ Doutora em Literatura Comparada pela UFF. Realizando Pós-Doutorado na UFF.

${ }^{2}$ Doutora em História pela PUCRS.

3 as a medium born with the twentieth century, is both a late-comer to and an avid, anashamed plagiarizer of earlier, literary forms of the Gothic.
} 
góticos seria um pouco simplista. Da mesma forma, também seria categorizar esse tipo de cinema em termos de um gênero específico, pois como Fred Botting nota, o gótico "excede gêneros e categorias"4 (BOTTING, 1996, p. 9 - Trad. Livre), tanto na literatura quanto no cinema. Algo que tentaremos mostrar ao longo deste trabalho enquanto analisamos o filme "Sangue de Pantera" (Cat People, 1942), de Jacques Tourneur, e suas relações com o contexto cultural e histórico estadunidense, bem como suas relações com as questões de monstruosidade feminina e controle.

Se no século XVIII o advento de romances como "O Castelo de Otranto" (1764), de Horace Walpole, marcaram um contraponto com a filosofia Iluminista da época, o boom dos monstros da Universal, no início dos anos de 1930 nos Estados Unidos, marcaram os medos do período mais obscuro da Grande Depressão. De acordo com David Skall, eles “ofereceram um espaço instintivo e terapêutico"5 (SKALL, 2001, p. 115 - Trad. Livre) à dura realidade. Uma década mais tarde, sob a sombra dos horrores da Segunda Guerra Mundial, o cinema estadunidense, por sua vez, vai trazer um novo tipo de horror, marcado pelo lançamento de "O Lobisomem" (The Wolf Man, 1941), que iria "[fabricar] um tipo completamente novo de monstro"6 (LANGENBACH, 2013, p. 94 - Trad. Livre), e misturaria licantropia com o tropo gótico de "O médico e o monstro" (1886), de Robert Louis Stevenson. A narrativa, explorando os aspectos do homem-animal e da natureza humana dual iria influenciar a RKO a fazer três filmes de horror produzidos por Val Lewton: "Sangue de Pantera" (Cat People, 1942), "A Morta Viva" (I Walked with a Zombie, 1943) e "O Homem-Leopardo" (The Leopard Man, 1943). O primeiro, que será o foco do nosso trabalho, produzido com um orçamento menor comparado a outras produções ${ }^{7}$, traz à tona uma história de paranoia, monstruosidade e repressão. No filme, roteirizado por DeWitt Bodeen, temos uma mulheranimal, a designer sérvia, Irina Dubrovna (Simone Simon), que mora em Nova York e conhece um arquiteto naval, Oliver Reed (Kent Smith), com quem se casa, mas não consegue consumar o casamento por medo de que sua sexualidade desperte uma antiga maldição que ela acredita carregar: a de que se transformaria em um animal predador quando sexualmente estimulada. Algo que Reed ignora e apenas considera como "conto de fadas”.

\footnotetext{
${ }^{4}$ exceed genres and categories.

${ }^{5}$ offered an instinctive, therapeutic space.

6 [fashioned] a whole new monster 'mythos'.

${ }^{7}$ Segundo Eric Somer (2004), a RKO impôs a Lewton que o orçamento de seus filmes feitos pelo estúdio não poderiam ter um orçamento acima de 150 mil dólares.
} 
A narrativa, que originalmente havia sido concebida como uma história contemporânea de guerra $^{8}$ (SKALL, 2001, p. 219-220), acabou perdendo esse elemento e mantendo apenas o enredo sobre a imigrante sérvia que leva uma maldição antiga para os Estados Unidos. Fortemente influenciado pelas teorias freudianas e, principalmente junguianas sobre o conceito de sombra (LANGENBACH, 2013, p. 96), o filme foi explorado incansavelmente sob o viés psicanalítico (BERKS, 1992, p. 26). No entanto, embora as discussões sobre a repressão e controle da sombra felina de Irena suscitadas pela crítica psicanalista sejam extremamente relevantes para a análise do filme, nos deteremos na construção visual da monstruosidade na figura da mulher e no controle exercido sobre ela a partir de uma analise sobre o cinema, sua influência gótica e o contexto histórico e cultural estadunidense.

Como afirmou Martin Scorsese e Michael Wilson, nos filmes de Tourneur, os personagens não estavam sob o controle de seus destinos, mas "eram movidos por forças que eles não compreendiam" (SCORSESE; WILSON, 2004, p. 116). Seja em um universo "real" ou sobrenatural, seus personagens estão sob constante ameaça. No entanto, é relevante entender quem representa a ameaça em filmes como "Sangue da Pantera" e de que forma essas questões dialogam com a sociedade do período.

Embora muito do que percebemos em filmes considerados góticos tenham sua origem na literatura, o cinema caracterizado como gótico estabelece uma relação direta com o expressionismo alemão. Juliane Langenbach (2013) identifica filmes alemães no início do século XX, como "O Estudante de Praga" (Der Student Von Prag, 1913) de Paul Wegener e obras expressionistas como "O Gabinete do Doutor Caligari" (Das Cabinet des Dr. Caligari, 1919) de Robert Wiene, como as primeiras expressões do que poderíamos compreender como o gótico no cinema. Segundo Lotte Eisner, o filme de Wegener "já apresenta muitas das qualidades que vão valorizar os filmes ditos 'clássicos' dos anos 20” (EISNER, 1985, p. 41), assim como a relação com o romantismo e a reprodução de um "clima fantástico".

O movimento do Expressionismo Alemão possui uma relação direta com o romantismo e o gótico na literatura, marcados por uma "atração pelo o que é obscuro e indeterminado" (EISNER, 1985, p.17) da cultura alemã, presentes nessas tradições. Esses elementos se expressaram visualmente na arte, e consequentemente, no cinema, resultando em uma mise-en-scène estilizada que serviu de influência a diversos filmes ao longo do século

\footnotetext{
${ }^{8}$ Cf.: Cat People had been originally conceived as a contemporary war story. In Lewton's first treatment, a Nazi Panzer division invades a Balkan village. The inhabitants put up no immediate resistance. They don't have to at night they are able to turn into giant werecats and kill their oppressors. Lewton imagined a village girl fleeing to New York, and taking the cat-people curse with her.
} 
XX, como os filmes de horror da Universal e da RKO nas décadas de 1930 e 1940, respectivamente, e o cinema noir estadunidense das décadas de 1940 e $1950^{9}$. Para Langenbach, "a função primária da estética visual do Gótico sempre foi evocar um clima sombrio e uma atmosfera misteriosa e arrepiante de mal e terror" (LANGENBACH, 2013, p. 20 - Trad. Livre). Esse tom é mantido por uma combinação de elementos, mas no caso do cinema alemão está atrelado diretamente à construção da mise-en-scène e de como os temas e personagens são apresentados visualmente.

Segundo E. Ann Kaplan, "Irena Dubrovna é desde o início marcada como estrangeira"10 (KAPLAN, 2007, p. 188 - Trad. Livre), e essa será uma das características fundamentais que a institui como diferente de todos do filme, principalmente de Oliver Reed (Kent Smith) e Alice Moore (Jane Randolph) - a amiga e, também, mulher interessada romanticamente por ele. No filme, ser estrangeira significa assumir uma forma monstruosa em relação a um corpo considerado normal. No entanto, a monstruosidade em "Sangue de Pantera" não se limita à forma animalesca de Irena, mas também está atrelada a sua feminilidade - marcada como perigosa, sexual e mortal -, que colocará a vida de todos em risco. Irena, como outros personagens da tradição gótica, possui uma dualidade que a conduzirá a uma batalha interna ao longo de sua jornada.

Jack Halberstam ${ }^{11}$ identifica a monstruosidade do romance gótico do século XIX como representativo daquilo que colocava à nação sob ameaça. Para ele "o monstro gótico representa várias respostas para a questão sobre quem deve ser removido da comunidade"12 (HALBERSTAM, 1995, p. 3 - Trad. Livre), e esses elementos continuaram presentes no cinema do século XX, sendo o filme de Tourneur um exemplo. Em contextos de discursos nacionais exacerbados, como na Segunda Guerra Mundial, essas discussões não são estranhas às ficções de Hollywood, mesmo que só tenham sido apresentadas de maneira simbólica. Sobre isso, Thomas Schatz observa que "nunca antes os interesses da nação e da indústria estiveram tão alinhados, e nunca antes o status do cinema como cinema nacional foi tão

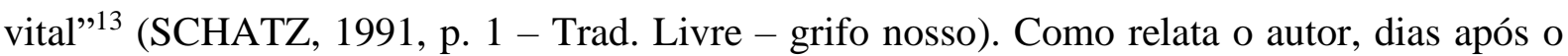

\footnotetext{
9 A popularização dos universos góticos no cinema se deve ao cinema de horror produzido pelo estúdio da Universal na década de 1930 (LANGENBACH, 2013).

${ }^{10}$ Irena Dubrovna is from the start marked as foreign.

${ }^{11}$ No ano da publicação do livro que utilizamos como referência neste artigo o referido autor publicava sob o nome de Judith. No entanto, em respeito ao nome que ele adota atualmente em suas publicações, optamos por usar o nome Jack ao longo do texto.

12 The Gothic monster represents many answers to the question of who must be removed from the community at large.

${ }^{13}$ never before had the interests of the nation and the industry been so closely aligned, and never had its status as national cinema so vital.
} 
ataque em Pearl Harbor, em dezembro de 1941, o presidente manifestou um interesse especifico em Hollywood como uma fonte de "distração, informação e propaganda" ${ }^{14}$, tanto para cidadãos como para soldados, algo que deve ser considerado quando se discute a produção hollywoodiana, uma vez que Hollywood e Washington tiveram uma relação direta no período no qual o país esteve em guerra ${ }^{15}$.

Filmes como "Sangue da Pantera" possuem um "nacionalismo óbvio", segundo E. Ann Kaplan (2007) e, neste caso, é relevante entender de que forma essas noções se encontram na história e como é possível estabelecer diálogos entre a ficção e a sociedade do período. De acordo com Halberstam “o romance gótico mapeia emaranhamentos de raça, nação e sexualidade na sua construção de um 'Outro""16 (HALBERSTAM, 1995, p. 14 Trad. Livre) e, se no caso de Drácula, como analisado por Halberstam, o conde é a antítese do que significa ser inglês, Irena, em "Sangue da Pantera", representa a antítese de um modelo de feminilidade estadunidense. Ela almeja um ideal de normalidade, pontuada no filme como “americana", contudo, ela nunca será percebida assim pelos outros personagens. Halberstam aponta para a xenofobia presente no romance gótico inglês do século XIX, elemento presente na narrativa do filme de Tourneur, considerando a maneira como Irena é representada como uma ameaça, principalmente para Oliver e Alice. Na cena em que Irena e Oliver estão comemorando o casamento esse sentimento fica claro quando um dos seus colegas de trabalho manifesta uma preocupação pelo fato de Irena ser "estranha". Para Scorsese e Wilson:

O território crepuscular de Tourneur era um labirinto. Suas jornadas eram perigosas incursões no desconhecido e as vezes no oculto. A realidade permanecia opaca e raramente as pessoas eram o que pareciam ser, elas ficavam na fronteira de um mundo escondido (SCORSESE; WILSON, 2004, p.119)

Irena Drubovna convive em um limiar fronteiriço da luz e da escuridão, uma batalha interna, até sucumbir ao que filme entende como sua natureza. O simbólico do claro-escuro se apresenta no filme de Tourneur como representativo dessa dualidade da personagem, mas também como algo que representa a ameaça dela para com os outros. É um discurso do bem

\footnotetext{
${ }^{14}$ Em junho de 1942 foi criado o Office of War Information (OWI) que tornou a relação entre o governo e Hollywood mais "formal e burocrática" (SCHATZ, 1999) durante o período do conflito.

${ }^{15}$ No final de 1942 praticamente um terço de toda produção hollywoodiana lidava diretamente com o esforço de guerra e foi marcado por filmes que retratavam eventos reais e cotidianos. Conforme Schatz (1999), o cinema noir destoou dessa tendência por representar um mundo sombrio, no entanto, o cinema de horror também pode ser pensado como um contraste dessa produção atual, mesmo que ainda possa ser lido em dialogo com o principal evento político do período.

${ }^{16}$ The Gothic novel charts the entanglement of race, nation, and sexuality in productions of otherness.
} 
contra o mal, dialogando com um binarismo marcante do período em que o filme foi produzido. No entanto, as linhas entre o claro-escuro se confundem na figura da protagonista que se sente assombrada por seu passado.

$\mathrm{Na}$ primeira sequência do filme, Irena e Oliver se conhecem e ele demonstra um interesse por ela. Ambos vão ao lugar onde Irena mora e, "uma vez dentro do apartamento, Irena enfatiza sua conexão com a escuridão e o mal, assim como ela continua a fazer durante a narrativa"17 (SOMER, 2014, p.199 - Trad. Livre). Na primeira vez que ela abre a porta de seu apartamento ele está iluminado de forma clara, mas há uma elipse de passagem do tempo em que a protagonista e Oliver estão em silêncio no escuro, e neste momento, ela afirma: "Eu gosto da escuridão. Ela é amigável"18 (Trad. Livre). Demonstrando que sua relação com a escuridão, que será associada com sua natureza ao longo do filme, é conflituosa.

Ao contar a história da invasão de sua vila na Sérvia por Mamelucos existem sombras projetadas sob o seu rosto. Essa história constitui a assombração de sua vida, um "fantasma" do qual não conseguirá se livrar. Antes da invasão ela conta a Oliver que o povo era bom, cristão e adorador de Deus, o que muda depois ao se tornarem adoradores de Satã, bruxas e más pessoas, segundo sua narrativa. Essa história marca de forma direta a batalha de Irena e sua tentativa de se enquadrar com o povo "bom e cristão", representado por Oliver e Alice, deixando de lado a maldição das mulheres que se transformam em felinos de grande porte.

Como o Halberstam nota, "monstruosidade (e o medo que isso dá origem) é historicamente condicionado"19 (HALBERSTAM, 1995, p. 6 - Trad. Livre) e tanto Somer (2014) como Kaplan (2007) afirmam que o fato de Irena ser estrangeira é diretamente relacionada à sua monstruosidade. No entanto, Kaplan vai além ao relacionar a pantera/Irena com um dos maiores inimigos dos EUA no período, os nazistas ${ }^{20}$. Independente de ser possível ou não nomear o que simbolicamente Irena representa, o texto do filme nos concede alguns elementos que caracterizam a protagonista como alguém que não é normal, portanto, diferente de modelo ideal de estadunidense branco. Como diz Oliver no início do filme "você é Irena. Você está aqui na America. Você é tão normal que está apaixonada por mim, Oliver Reed, um americano bom e comum"21 (Trad. Livre). Nessa fala, Oliver tenta convencer Irena

\footnotetext{
17 once inside the apartment, Irena stresses her connection to darkness and evil, as she continues to do throughout the narrative.

${ }^{18}$ I like the darkness. It is friendly.

${ }^{19}$ Monstrosity (and the fear it gives rise to) is historically conditioned.

${ }^{20}$ Segundo a interpretação de E. Ann Kaplan (2007) é possível ler no filme uma representação inconsciente de iconografia nazista, a autora exemplifica com algumas roupas usadas por Irena e na figura da cat woman que a protagonista encontra no inicio da história.

${ }^{21}$ You're Irena. You're here in America. You're so normal that you even in love with me, Oliver Reed, a good, plain americano.
} 
que as histórias que ela escutava quando criança eram apenas invenções. A oposição que ele constrói entre a terra dela e os EUA é relevante para compreender algumas ideias do filme e a maneira como, não somente Irena tenta se enquadrar a um ideal de normal, mas como todos os personagens do filme também tentam fazer o mesmo com ela. Nesse caso, os Estados Unidos e sua cultura são colocados como ideal de normalidade. Ideal que está atrelado a relação heterossexual formalizada pelo casamento.

Desde o inicio, o filme é permeado por imagens de felinos. No entanto, o animal que representará a forma monstruosa de Irena é visto como uma besta perversa, que precisa ser contida na jaula do zoológico - cenário constante da primeira à ultima cena de "Sangue da Pantera". A protagonista expressa uma vontade ao longo do filme de reprimir sua natureza, mas existe também uma pressão por parte de todos, principalmente dos homens (marido e psiquiatra) de tentar domesticar esses sentimentos. No final do filme, inclusive, a intenção de contê-la - como a pantera do zoológico - em uma instituição mental é manifestada explicitamente.

A ideia de monstruosidade em contraposição a de domesticidade, nesse sentido, é usada para marcar uma das diferenças principais entre a Irena e Alice. A natureza selvagem, independente e inconformada de Irena, que é apontada como monstruosa e repreensível, é o que condena a protagonista no final da narrativa, enquanto a domesticidade, característica de um ideal de feminilidade que Alice abraça, a transforma em mulher ideal para ficar com Oliver. É relevante notar que ao longo do filme a pantera não é o único felino a aparecer, a natureza "perversa" e "selvagem" de Irena é contrastada por felinos "domésticos" que aparecem em três cenas. Neste sentido, Eric Somer entende a pantera como representativa dessa dita natureza selvagem e predatória da protagonista, ao passo que "o gato doméstico se torna a metonímia da sexualidade "segura" de Alice" (2004, p.201 - Trad. Livre), já que esses felinos aparecem relacionados a ela nos três momentos.

Irena, durante todo o filme, resiste às tentativas dos outros personagens de enquadrá-la e aos poucos é vista também por Oliver como alguém “estranha”. E. Ann Kaplan observa que “Oliver sugere que a anormalidade de Irena é resultado dela não ser 'Americana', enquanto que a normalidade de Oliver é parte de sua americanidade" ${ }^{22}$ (KAPLAN, 2007, p.188 - Trad. Livre). Essa "anormalidade" de Irena é também construída visualmente, através da iluminação e do figurino, principalmente. Desde o primeiro momento, as sombras e a

22 Oliver implies that Irena's abnormality is a result of her not being 'American', whereas Oliver's normality is part of his Americanness. 
escuridão marcam sua presença em cena, a distanciando cada vez mais dos personagens representativos da normatividade branca estadunidense do período.

Em "Sangue da Pantera", Tourneur trabalha junto com o diretor de fotografia Nicholas Musuraca para criar um universo sombrio de luz e sombras em que é possível perceber a influencia dessa construção visual de um espaço que poderia ser considerado gótico. É notável como as sombras vão aos poucos tomando conta dos espaços, inclusive com o uso maior de cenários noturnos da metade para o final do filme. Os filmes da RKO, segundo Somer (2004), tinham como foco criar tensão, colocando uma importância maior no que poderiam sugerir do que efetivamente mostrar. Tanto ele quanto Thomas Schatz (1999), referem-se à criação de uma atmosfera, sendo este um elemento fundamental de filmes como "Sangue de Pantera".

A maneira como Siegfried Kracauer caracteriza a visualidade de filmes como "O Gabinete do Doutor Caligari" também é relevante para discutirmos a forma que o claroescuro é utilizado no cinema de Tourneur. É uma visualidade que caracteriza um universo assombrado pelo passado, por forças incontroláveis. Para ele, "o filme espalha uma atmosfera onipresente de horror" 23 (KRACAUER, 1966, p. 74 - Trad. Livre), ressaltando algo que se manifesta ao longo da narrativa de Caligari. Lotte Eisner também se refere a essa atmosfera de horror quando trata do cinema de F.W. Murnau e dessa sensação constante de que algo está sob ameaça. Em “Sangue de Pantera”, por sua vez, é perceptível como as sombras e os espaços escuros vão tomando um espaço maior na medida em que a natureza de Irena torna-se algo incontrolável para ela.

Ao longo da história é relevante notar como o discurso do filme posiciona seus personagens. Quem é representado na escuridão e na luz, e de que forma esses elementos podem ser discutidos conjuntamente a uma ideia de ameaça à norma e monstruosidade. Os três filmes de horror que Tourneur fez para a RKO possuem algumas similaridades. A relação com a escuridão, o medo do escuro, e quem pertence a esse universo de sombras, assim como quem são aqueles que representam a ameaça para os personagens brancos e estadunidenses. Esses elementos são mais presentes em "Sangue da Pantera" e "A Morta Viva"24 - inspirado no romance gótico Jane Eyre, de Charlotte, Brontë -, mas não são estranhos ao "O Homem

\footnotetext{
${ }^{23}$ The film spreads an all-pervading atmosphere of horror.

${ }^{24}$ Sobre esse filme que se passa em uma ilha do Caribe, Robin Coleman afirmou: "O que fica evidente nesse filme é que a negritude é tão infecciosa que coloca os brancos em risco, especialmente as mulheres brancas, que são enfraquecidas pelo seu encontro com a negritude. No filme, duas mulheres brancas se tornam vitimas da cultura negra. A primeira fica obcecada por mitos e pelo poder do vodu e, por isso, transforma uma outra branca indefesa em zumbi” (2019, p.131).
} 
Leopardo" que se passa em uma cidade do Novo México com a maioria dos personagens sendo de origem hispânica.

Na leitura que Patrick Keating faz sobre a iluminação no cinema noir, e que pode ser aplicada neste caso, o autor afirma que primeiramente não devemos nos focar apenas nas sombras. Entendemos que é relevante analisarmos a relação entre esses espaços marcados pela luz, já que "os padrões de luz e sombra revelam um o outro e se cruzam para produzir camadas de significados" ${ }^{25}$ (KEATING, 2013, p. 281 - Trad. Livre). Esses espaços de claroescuro no filme podem funcionar como simbólico de marcadores de diferenças entre Irena, estrangeira e monstruosa, e Oliver e Alice, brancos estadunidenses. Segundo Somer "a unidade de horror de Lewton dependia do poder sugestivo da escuridão, do uso elaborado de sombras opressivas e de temas pessimistas"26 (SOMER, 2004, p. 194 - Trad. Livre). As sombras que se intensificam ao longo do filme podem ser lidas como uma consequência da ameaça de Irena para com os outros, não somente em um sentido relativo à vida, mas relativo a um modo de vida também. Conforme Kathryn Woodward nota, "a identidade depende da diferença" (WOODWARD, 2014, p. 9), e a afirmação dos que representam um ideal de masculinidade e feminilidade branca estadunidense depende do marcador da diferença entre eles e Irena. Entre os "normais" e a "monstruosidade" que os ameaça. Algo que fica explícito até mesmo nas roupas das personagens femininas, como comentado anteriormente: Irena ganha figurinos cada vez mais escuros no decorrer do filme, enquanto Alice permanece com figurinos de cores claras.

Segundo Halberstam, no romance gótico o corpo monstruoso é uma “identidade negativa" em relação ao considerado humano e normal. Para ele: "monstros precisam ser tudo que os humanos não são e, ao produzir um humano negativo, esses romances dão espaço para a invenção do humano como branco, masculino, classe média e heterossexual"27 (HALBERSTAM, 1995, p. 22 - Trad. Livre). Algo que nos permitem dialogar também com a própria construção de feminilidade de figuras como Irena Dubrovna em um Estados Unidos da década de 1940, uma década na qual as mulheres, no cinema, ganham uma quantidade significativa de papéis que iriam reforçar a ideia do feminino estar ligado ao disruptivo, causadora de violência e ruína alheia - principalmente do homem. Como nota Molly Haskel, é nessa época que a mulher, no cinema, começa a cair do pedestal e "não para quando atinge o

\footnotetext{
${ }^{25}$ the patterns of light and shadow inform each other, intersecting to produce layers of meaning.

${ }^{26}$ Lewton's horror unit relied on the suggestive power of the darkness, the elaborate use of opressive shadows and pessimistic themes.

${ }^{27}$ Monsters have to be everything the human is not and, in producing the negative human, these novels make way for the invention of human as white, male, middle class, and heterosexual.
} 
chão"28 (HASKELL, 2016, p. 189 - Trad. Livre). Das femme fatales do noir às amaldiçoadas por crenças antigas, como Irena, as mulheres passam a integrar uma ambiguidade que vai constituir o que Haskell nota como uma fantasia masculina "onde o poder dela de destruir era uma projeção dos sentimentos de impotência dos homens" ${ }^{29}$ (HASKELL, 2016, p. 190 Trad. Livre). Algo bastante compreensível dentro de um contexto de guerra e com um maior número de mulheres entrando no mercado de trabalho e adquirindo uma certa autonomia financeira. Como destaca a historiadora Stephanie Coontz:

\begin{abstract}
A Segunda Guerra Mundial trouxe uma grande mudança no trabalho feminino. Entre 1940 e 1945, a força de trabalho feminina aumento mais de 50\%. (...) A guerra eliminou várias barreiras para a contratação de esposas, mães e mulheres mais velhas. Também proporcionou a milhares de mulheres que já estavam trabalhando a experiência de mobilidade ocupacional e as recompensas de um trabalho desafiador e bem pago (...) A longo prazo, a Segunda Guerra Mundial parece ter aumentado o gosto das mulheres pelo trabalho remunerado. ${ }^{30}$ (COONTZ, 2016, Ed. Kindle Trad. Livre)
\end{abstract}

A independência de Irena, em "Sangue de Pantera", é marcada na narrativa fílmica desde seu início. Ela mora sozinha em Nova York, tem uma profissão respeitável e é para a casa dela que o casal vai, desde o primeiro encontro. No entanto, a partir do momento em que ela conhece Oliver, ela começa cada vez mais a se sentir invadida não apenas por ele, mas pelas outras pessoas que ele traz para a relação. Sua primeira consulta com o psiquiatra Judd, na qual ela deveria conversar sobre a maldição e seu medo de se relacionar fisicamente, é tornada uma questão pública por Oliver quando ele compartilha o problema com Alice, que é, inclusive, quem indica o psiquiatra ao amigo. Uma Irena compreensivelmente aborrecida indaga o marido, "mas Oliver, como você pode conversas com ela sobre essas coisas? Coisas tão íntimas sobre mim?"31 (Trad. Livre), apenas para escutar o marido dizer que Alice é "uma pessoa tão boa"32 (Trad. Livre) que qualquer coisa poderia ser contada a ela. Iniciando uma rivalidade entre as duas personagens, que a partir desse momento vão perceber uma a outra como "ameaças".

Irena, descontente com a invasão permitida por Oliver, começa a sentir ciúmes de Alice, o que nos leva a duas cenas emblemáticas, permeadas pelo jogo de luz e sombra

\footnotetext{
${ }^{28}$ didn't stop when she reached the ground.

${ }^{29}$ where her power to destroy was a projection of man's feeling of impotence.

${ }^{30}$ The Second World War brought a major shift in women's work. Between 1940 and 1945, the female labor force increased by more than 50 percent. (...) The war eliminated many barriers to the employment of wives, mothers, and older women. It also gave thousands of women who had already been working their first experience of occupational mobility and the rewards of challenging, well-paid work (...) In the long run, the Second World War seems to have increased women's taste for work.

${ }^{31}$ But Oliver, how can you discuss such things? Such intimate things about me?.

${ }^{32}$ such a good egg.
} 
característico do filme. A primeira delas sendo a cena do ônibus, na qual Irena começa a perseguir Alice pela rua, até que seus passos cessam e apenas é possível escutar o rugir de um felino no momento em que o ônibus abre a porta para Alice entrar ${ }^{33}$. A seguir, temos a cena da piscina, onde Irena, novamente, vai atrás de Alice e cria um ambiente de medo no qual a amiga de Oliver, no meio iluminado da piscina, escuta sons característicos de um animal felino enquanto a câmera mostra sombras pelas paredes que não nos permitem identificar com certeza se existe ou não um animal selvagem no ambiente.

A criação do suspense, nas duas cenas, é atrelada à atmosfera e ao poder imaginativo que as sombras incitam, sugerindo que o medo de Alice pode ser meramente psicológico ou não. Como observa Andrew Syder "o filme de horror gótico reconhece que existem coisas potencialmente desconhecidas no mundo, coisas que podem ameaçar as leis do mundo como o conhecemos" ${ }^{34}$ (SYDER, 2002, p. 83 - Trad. Livre), no qual tudo que é relacionado ao escuro é potencialmente perigoso e monstruoso e tudo que é ligado a cores claras traz uma certa tranquilidade. Sobre essa relação, Kaplan sugere que "o branco não é apenas mais uma categoria entre várias outras: é a categoria através da qual qualquer outra diferença é produzida como 'Outro""35 (KAPLAN, 2007, p.192 - Trad Livre). E, nesse sentido, a luz também pode ser vista como um simbólico racial e os espaços claro-escuro tem como medida a luz, que no caso de "Sangue da Pantera", são representados pelo estadunidense, branco e cristão e pelos valores que serão defendidos no filme.

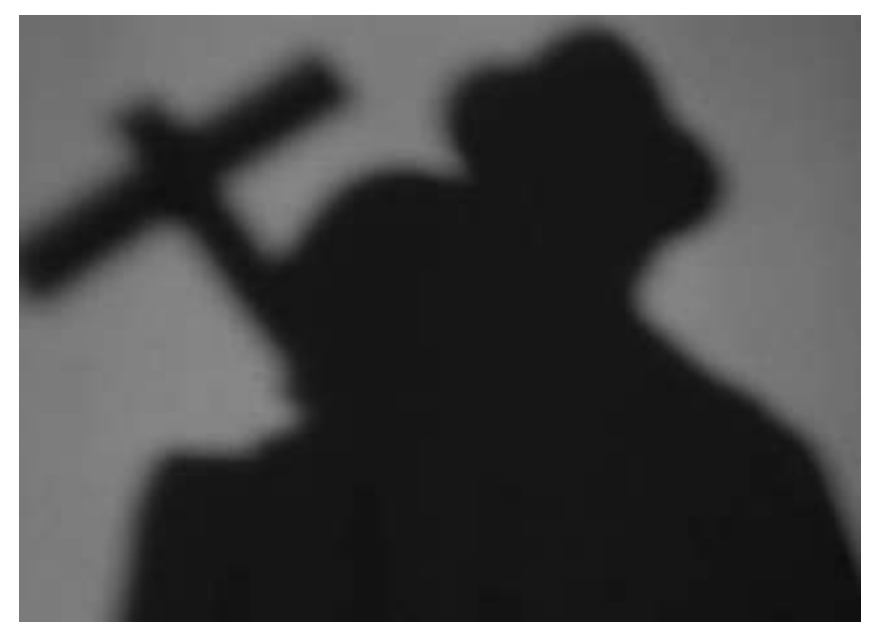

Figura 1: “Sangue da Pantera”, Dir. Jacques Tourneur, 1942.

\footnotetext{
${ }^{33}$ Segundo Fred Botting (1996), no século XIX a literatura gótica explora a paisagem da cidade como esse espaço de ameaça e violência. Ruas escuras, labirínticas e claustrofóbicas em um contexto de modernidade e industrialização. Aspectos recuperados pelo filme de Tourneur.

${ }^{34}$ the Gothic horror film acknowledges that there are potentially unknown things in the world, things to threaten the laws of the world as we know them.

${ }^{35}$ Whiteness is not just one category among many: it is the category through which all other differences are produced as Other.
} 
A imagem acima pode ser representativa dessa discussão. Oliver e Alice estão no escritório onde trabalham à noite, o ambiente está pouco iluminado e sombrio, e logo um enorme felino surge no ambiente ameaçando o casal. Oliver o chama de Irena, e para se defender pega uma régua $\mathrm{T}$ que está na parede. Nesse momento, o diretor deixa de filmar os dois atores para focar nas sombras projetadas pela pouca luz, e como se o personagem estivesse com uma cruz na mão, ele afirma: "Em nome de Deus, nos deixe em paz"36 (Trad. Livre). Logo, o felino sai do local. Essa cena nos remete a ideia de que os dois são representativos da sociedade estadunidense que está sob ameaça pela forma monstruosa de Irena.

Segundo Fred Botting (1996), as sombras são um elemento presente na estética gótica e constam como uma representação metafórica de ameaça à razão e à luz. O que está ambientado na escuridão representa o desconhecido, e em um mundo Iluminista, isso deve ser temido. Conforme Misha Kavka, "lançar sombras é uma forma de manipular o espaço" „37 (KAVAKA, 2002, p. 214 - Trad. Livre), projetando algo/alguém em tamanho maior afim de causar ameaça ou representando uma força/ser de outro plano que está a assombrar. Esse efeito é constantemente utilizado no filme de Tourneur, tanto nas cenas mencionadas da perseguição na rua e na piscina, como em outras que nos remetem sempre a ameaça de Irena e a vulnerabilidade dos outros personagens.

Luz e sombra, segundo Kevin Chabot também aparece nos filmes de Lewton "como símbolo de repressão e do inconsciente" ${ }^{38}$ (CHABOT, 2013, p. 21 - Trad. Livre). Detalhe particularmente importante em "Sangue de Pantera", pois além do suspense, representa o estado ambíguo e desorientado de Irena, causado, em grande medida, pela invasão de Oliver à sua privacidade - que a coloca em uma posição de mentalmente perturbada aos olhos dos personagens - juntamente com a perda gradual de autonomia que ela parece sofrer ao longo do filme. Seu medo, por outro lado, também está diretamente ligado à impossibilidade de se sentir parte daquele ambiente asséptico estadunidense como um todo, com todos seus valores cristãos, e onde a sexualidade e a independência feminina são percebidas como ameaça. Como defende Barbara Creed, normalmente, quando as mulheres são retratadas como monstruosas, isso está atrelado a maternidade ou a sexualidade, sendo mais comum, no entanto, estar conectada a ideia de desejos sexuais (CREED, 1993, p. 7). Para a pesquisadora:

\footnotetext{
${ }^{36}$ In the name of God, leave us in piece.

${ }^{37}$ casting shadows is one way of manipulating space.

${ }^{38}$ as sign of repression and the unconscious.
} 
A definição de pecado/abjeção como algo que vem de dentro abre espaço para posicionar a mulher como enganosamente traiçoeira. Ela pode parecer pura e linda por fora, mas o mal pode, no entanto, estar dentro. É esse estereótipo de mal feminino - bonito por fora/corrupto por dentro - que é tão popular nos discursos patriarcais sobre a natureza má da mulher. Essa visão dicotômica da mulher é central para a representação das mulheres assassinas nos filmes de vampiros e outros de horror como Sangue de Pantera, Repulsa ao Sexo, Sisters e Atração Fatal. ${ }^{39}$ (CREED, 1993, p. 42 - grifos da autora - Trad. Livre)

"Sangue de Pantera" não mostra em nenhum momento a transformação de Irena; a abjeção da personagem está dentro, ligada aos desejos que não podem ser manifestados e os quais os homens da narrativa temem, ao mesmo tempo que desejam. Ela aparece como mulher ou diretamente como animal em cena, monstruosidade que ganha força com as tentativas de controle dos personagens masculinos. Oliver, apesar de saber da maldição, pede Irena em casamento, negando a verdade da personagem, que ele só irá admitir na última cena, quando vê o corpo da mulher/pantera no chão do zoológico e diz para Alice "ela nunca mentiu para nós" ${ }^{40}$ (Trad. Livre). O psiquiatra, Dr. Judd, por sua vez, estabelece uma relação de poder com Irena bastante problemática, como nota Phyllis Chesler ao analisar as relações entre psiquiatras e pacientes mulheres em seu estudo Women and Madness. Para ela:

\begin{abstract}
De um ponto de vista financeiro, o terapeuta e não a paciente é o empregado. Psicologicamente, no entanto, a mulher é tão - se não mais - uma dependente aqui como ela o é em outras esferas. Ambas instâncias normalmente envolvem uma figura masculina mais velha e uma figura feminina mais nova. O homem, "inconscientemente", transmite sinais de poder, "amor", sabedoria e proteção. Sinais que a mulher foi condicionada a responder automaticamente. Tal transação entre paciente e terapeuta, eufemisticamente chamada de "sedução" ou "parte do processo de tratamento", é legalmente uma forma de estupro e, psicologicamente, uma forma de incesto. ${ }^{41}$ (CHESLER, 2005, p. 194 - Trad. Livre)
\end{abstract}

Judd insinua seu desejo pela personagem quando sugere para Irena durante uma sessão, como forma de resolver o problema, "e se eu te beijasse?"42 (Trad. Livre). Irena

\footnotetext{
${ }^{39}$ The definition of sin/abjection as something which comes from within opens up the way to position woman as deceptively treacherous. She may appear pure and beautiful on the outside but evil may, nevertheless, reside within. It is this stereotype of feminine evil - beautiful on the outside/corrupt within - that is so popular within patriarchal discourses about woman's evil nature. This dichotomous view of woman is central to the representation of the female killers in the vampire film and other horror texts such as Cat People, Repulsion, Sisters and Fatal Attraction.

${ }^{40}$ She never lie to us.

${ }^{41}$ From a financial point of view, the therapist and not his patient is the employee. Psychologically, however, the female is as much - if not more - a dependent supplicant here as she is elsewhere. Both instances generally involve an older male figure and a young female figure. The male transmits "unconscious" signals of power, "love", wisdom, and protection, signals to which the female has been conditioned to respond automatically. Such a transaction between patient and therapist, euphemistically termed "seduction" or "part of the treatment process", is legally a form of rape and psychologically, a form of incest".

42 and if I were to kiss you?
} 
responde: "apenas sei que não gostaria de ser beijada por você"43 (Trad. Livre) e, ao ser rejeitado, Judd a ameaça falando que "poderia ir ao conselho e colocar você [Irena] em uma instituição para observação"44 (Trad. Livre). Explicitando a necessidade dela ceder ao desejo masculino para não ser considerada mentalmente incapacitada. A suposta doença mental de Irena é também o que permite com que Oliver considere desfazer o casamento sem se tornar uma espécie de vilão. Judd aponta ao amigo, no final da película, duas alternativas: colocar Irena em uma instituição para observação e controle ou pedir a anulação do casamento. Em uma cena didática, comprometida com a manutenção dos bons costumes cristões, brancos e estadunidenses (talvez inserida, em grande medida, por causa do Código Hays de $1934^{45}$ ), Oliver decide que precisa "cuidar" de Irena, mesmo que isso implique que ele não poderia se casar com Alice - evidenciando, novamente, uma tentativa de tirar a autonomia da protagonista, mesmo caso eles não fossem mais um casal.

Frente a todas essas ameaças, Irena, no entanto, assume seu lado monstruoso e, além de pedir para Oliver a deixar sozinha após ele anunciar que amava Alice, na segunda investida de Judd, a protagonista não o rejeita verbalmente, mas se transforma em uma pantera que podemos ver atacar o psiquiatra através das sombras projetadas nas paredes do apartamento. O beijo entre os dois personagens marca, assim, a personificação da imagem monstruosa que era apenas assumida como possível de se concretizar pelos personagens da trama. O gótico, segundo Weinstock, "é um gênero que foca no passado e em paixões imoderadas e ingovernáveis"46 (WEINSTOCK, 2017, p. 1 - Trad. Livre), e Irena, seguindo essa tradição, extravasa sua ancestralidade "estranha" e monstruosa e assume controle da própria existência e de seus desejos ao atacar quem a ameaçava e ao libertar a pantera que ela frequentemente visitava no zoológico utilizando uma chave roubada do zelador.

É evidente que no cinema de horror da década de 1940 - com o Código Hays e um contexto de Segunda Guerra Mundial -, a transgressão de Irena não seria aceita,

\footnotetext{
${ }^{43}$ I only know that I should not like to be kissed by you.

${ }^{44}$ I could go before a board and have you put away for observation.

${ }^{45}$ Oficialmente chamado de The Motion Picture Production Code, esse código de autoregulação da indústria foi criado para evitar que os filmes lançados por Hollywood fossem censurados em cada cidade por motivos diferentes. A pedido da MPPDA (Motion Picture Producers and Distributors of America) em 1930, o padre jesuíta Daniel A. Lord e o jornalista católico Martin Quigley elaboraram uma lista detalhada de temas que deveriam ser observados nos filmes produzidos em Hollywood, como "obscenidades", "vulgaridades", nudez, respeito à religião e nação, etc. (LEWIS, 2008). Como afirmou Thomas Schatz (1999), é possível notar o caráter moral dessas regras que dominaram a produção fílmica por mais de três décadas. No entanto, de acordo com Jon Lewis (2008), houve uma resistência por parte dos estúdios e esse Código, que ficou mais conhecido como Código Hays, só foi efetivado em 1934.

${ }^{46}$ is a genre that focuses on the past and immoderate, ungovernable passions.
} 
diferentemente da transgressão de outros personagens, como Oliver ${ }^{47}$. "Sangue de Pantera", fortemente influenciado pela estética gótica e pautado em mitos de povos antigos sobre bruxas e maldições, utiliza a história de monstruosidade de Irena para tratar de angustias do período. Assim, se no início do filme a câmera mostra uma placa dentro do zoológico com os dizeres "Não deixa que ninguém diga, e diga para sua vergonha que tudo aqui era bonito até você aparecer"48 (Trad. Livre), ele termina com a projeção de um trecho de um poema de John Donne, no qual se lê "mas negro pecado revelou-se na noite sem fim/ o meu mundo, duas partes, ambas devem morrer" 49 (Trad. Livre). A estrangeira é marcada logo no início como o que será disruptivo no mundo perfeito de Oliver através de símbolos que aparecem no filme - como a placa e o próprio desenho no qual Irena está trabalhando na primeira cena, de uma pantera sendo atravessada por uma espada. Da mesma forma, o filme justifica sua destruição. Em um momento de nacionalismo exacerbado, como o da Segunda Guerra Mundial, tudo que não é o padrão estadunidense branco, cristão e masculino precisa ser destruído. A mulher independente e os desejos sexuais dela, marcados pela animalidade de Irena, pelas sombras e pela cor preta no filme, eram uma ameaça muito grande à nação.

\section{REFERÊNCIAS}

BERKS, John. "What Alice Does: Looking Otherwise at "The Cat People"”. In: Cinema Journal, vol 32, n.1, 1992: p. 26.42.

BOTTING, Fred. Gothic. New York: Routledge, 1996.

CHABOT, Kevin. "Bodies without Borders: Body Horror as Political Resistance in Classical Hollywood Cinema”. (Dessertação de Metrado) Ottawa: 2013. Disponível em: < https://curve.carleton.ca/4435f807-54e2-46ce-b3c8-81ad650766cf>. Acesso em 24 ago. de 2020.

CHESLER, Phyllis. Women and Madness. Chicago: Lawrence Hill Books, 2005.

COLEMAN, Robin R. Means. Horror Noire: a representação negra no cinema de terror. Rio de Janeiro: DarkSide Books, 2019.

COONTZ, Stephanie. The Way We Never Were: American Families and the Nostalgia Trap. New York: Basic Books, 2016. Edição Kindle.

\footnotetext{
${ }^{47}$ No referido Código Hays, representações de adultério não eram permitidas (LEWIS, 2008), no entanto, a relação de Oliver e Alice, que pode ser entendida como adultério é perdoada no filme, podendo ser lida como uma ação justificada devido a situação da esposa.

${ }^{48}$ Let no one say, and say it to your shame. That all was beauty here, until you came.

${ }^{49}$ But black sin hath betrayed to endless night / My world, both parts, and both parts must die.
} 
CREED, Barbara. The Monstrous-Feminine: Film, Feminism, Psychoanalysis. Abingdon: Routledge, 1993.

EISNER, Lotte H. A Tela Demoníaca: As Influencias de Max Reinhardt e do Expressionismo. Paz e Terra: Rio de Janeiro, 1985.

KEATING, Patrick. "Out of the Shadows: Noir Lighting and Hollywood Cinematography". In: SPICER, Andrew; HANSON, Helen (edited by). A Companion to Film Noir. Sussex: Wiley Blackwell, 2013.

KRACAUER, Siegfried. From Caligari to Hitler: a psychological History of the German film. Nova Jersey: Princeton University Press, 1966.

HASKELL, Molly. From Reverence to Rape: the Treatment of Women in the Movies. Chicago: The University of Chicago Press, 2016.

HALBERSTAM, Judith. Skin Shows: Gothic Horror and the Technology of Monsters. Duke University Press: Durham and London, 1995.

KAPLAN, E. Ann. “The 'Dark Continent' of Film Noir: Race, Displacement and Metaphor in Tourneur's Cat People (1942) and Welles's The Lady from Shanghai (1948)". In: KAPLAN, E. Ann (ed.). Women in Film Noir. London: BFI Publishing, 2007.

KAVKA, Misha. "The Gothic on screen". In: HOGLE, Jerrold E. The Cambridge Companion to Gothic Fiction. Cambridge: Cambridge University Press, 2002.

LANGENBACH, Juliane. "Gothic shadowplays: the evolution of Gothic film and its visual aesthetic from the Gothic novel to the cinema of Jacques Tourneur, Roger Corman, and Tim Burton”. Zurique: 2013. Disponível em: < https://www.zora.uzh.ch/id/eprint/164247/> Acesso em 20 de ago. de 2020.

LEWIS, Jon. American Film: A History. New York and London: W. W. Norton \& Company, 2008 .

SANGUE de Pantera (Cat People). Direção: Jacques Tourneur. Estados Unidos: RKO, 1942. $73 \mathrm{~min}$.

SCHATZ, Thomas. Boom and Bust: American Cinema in the 1940s. Berkeley/Los Angeles: University of California Press, 1999.

SCORSESE, Martin; WILSON, Michael Henry. Uma Viagem Pessoal Pelo Cinema Americano. São Paulo: Cosac Naify, 2004.

SKALL, David J. The Monster Show: A Cultural History of Horror. New York: Farrar, Straus and Giroux, 2001.

SOMER, Eric. "The Noir-Horror of Cat People (1942)". In: SILVER, Alain; URSINI, James (edited by). Film Noir Reader 4: The Crucial Films and Themes. Limelight Editions: New Jersey, 2014. 
SYDER, Andrew. "Knowing the Rules: Postmodernism and the Horror Film". In: Axes to Grind: Re-Imagining the Horrific in Visual Media and Culture, Special Issue of Spectator. N. 22 vol 2 (2002), p. 78-88.

WEINSTOCK, Andrew. "Introduction: The American Gothic". In: WEINSTOCK, A. The Cambridge Companion to American Gothic. New York: Cambridge University Press, 2017.

WOODWARD, Kathryn. Identidade e Diferença: uma introdução teórica e conceitual. In: SILVA, Tomaz Tadeu da. (org.). Identidade e Diferença: A perspectiva dos Estudos Culturais. Petrópolis, RJ: Vozes, 2014.

Recebido em 28/9/2020.

Aceito em 07/12/2020. 